\title{
The effects of dexamethasone on $17 \beta$-HSD1 levels at the rat optic nerve
}

\author{
Chuanzhi Liu ${ }^{\mathrm{a}}$, Guozhong $\mathrm{Xu}^{\mathrm{a}}$, Ping Gong ${ }^{\mathrm{a}}$ and Zuobin Wang ${ }^{\mathrm{b}, *}$ \\ ${ }^{a}$ School of Life Science and Technology, Changchun University of Science and Technology, Changchun, \\ Jilin 130022, China \\ ${ }^{\mathrm{b}}$ International Research Centre for Nano Handling and Manufacturing of China, Changchun \\ University of Science and Technology, Changchun, Jilin 130022, China
}

\begin{abstract}
Dexamethasone (DEX) is associated with many inflammation and metabolic diseases. We analyzed the effects of DEX on the expression of estrogen metabolism enzyme $17 \beta$-HSD1 at the optic nerve. Rats were treated with different concentrations of intraperitoneal DEX. Western Blot analysis showed that $17 \beta$-HSD protein was expressed in the optic nerve tissue. The enzyme was detected by immunohistochemistry on the terminal foot of Muller cells from the ganglion cell layer of rat retina. ELISA analysis showed that the $17 \beta$-HSD1 protein expression of DEX-treated group is 2.4 fold comparing to the control group. The results indicated that DMXS sodium phosphate might modulate the expression of $17 \beta$-HSD1 protein in optic tissue. This study sheds light on understanding of the relationship among DEX, 17 $\beta$-HSD presence and distribution of visual neural systems. At the same time, DEX treatment affects the athletic ability and memory of the animals. Compared with the control group, the experimental group showed slow response to stimulation, inertia, depression, cowardice and lack of appetite. The results of ethology experiments showed that all the parameters decreased by $15-30 \%$.
\end{abstract}

Keywords: Dexamethasone, $17 \beta$-HSDs, rat optic nerve

\section{Introduction}

Dexamethasone is a kind of glucocorticoid, it has anti-inflammatory, and anti-endotoxin effects, suppress the immune response and the resistance to shock and enhance the stress response among other pharmacological effects, so it is widely used for the treatment of many diseases [1,2]. DEX may cause hypokalemia syndrome, peptic ulcers, pancreatitis, children's growth is restrained, and worsen glaucoma, cataract and diabetes [3]. As a steroid hormone, it is degraded by many enzymes such as $3 \alpha-\mathrm{HSD}$, $3 \beta$-HSD, $11 \beta$-HSD, $17 \beta$-HSD, SDR [4,5]. The $17 \beta$-HSDs family is mainly responsible for synthesis and degradation of estrogens and androgens [6,7]. In recent years, studies have shown that they are also taken part in DEX metabolism [8,9]. The distribution of this enzyme family is not restricted to reproductive and endocrine systems [10,11].

The relationship between hormones and eye diseases has recently gained increased attention. The corneal thickness changes along the female menstrual cycle. It is thicker at the time of ovulation to be

\footnotetext{
${ }^{*}$ Corresponding author: Zuobin Wang, International Research Centre for Nano Handling and Manufacturing of China, Changchun University of Science and Technology, Changchun, Jilin 130022, China. Tel.: +86 18643020302; Fax: +86 431 85583099; E-mail: duguchuanzhi@163.com.
}

0928-7329/19/\$35.00 (c) 2019 - IOS Press and the authors. All rights reserved

This article is published online with Open Access and distributed under the terms of the Creative Commons Attribution NonCommercial License (CC BY-NC 4.0). 
gradually thinner up to the menstrual period $[12,13]$. The incidence of cataracts is higher in woman than in men, especially in postmenopausal women, because of the lack of estrogens that is a well-known risk factor [14]. Hormones also play important roles in neural regulation and protection, avoiding neural degeneration $[15,16]$. It has also been found that estradiol can enhance the viability of primary nerve cell cultures. The activation of estrogen receptors result in nerve protective effects, improve the interaction between antioxidants and intracellular signal transduction pathways, inhibit apoptosis, enhance synaptic sprouting and axonal regeneration, and improve the function of cholinergic nerves $[17,18]$.

In the early 90s, the steroid hormonal, pregnenolone, dehydroepiandrosterone and progesterone were found in the human retina [19]. In 2008, hormonal receptors were located at the rat retina by immunohistochemistry [20]. Zhang designed a study to explore the ovarectomy and sham-ovarectomy for studying the effect of estrogen on ocular diseases and its role in retinal neovascularization. He found decrease of estrogen level in blood contributes to retinal neovascularization, but too much damage to the optic nerve and cause SD rats visual deterioration [21]. Garg et al. measured the serous steroid and $24 \mathrm{~h}$ urinary steroid content in 30 (central serous chorioretinopathy, CSC) patients and the control group, and found that the steroid content in the patients group was significantly higher than control group, and the female patients were significantly higher than the male patients. Steroid hormones are involved in regulating choroidal microcirculation, causing retinal pigment epithelium damage and local ion flow changes in high dosage. The local metabolism of hormones plays an important role in gene regulation, nerve regulation and immune regulation [22]. Several studies demonstrated that hormones and the related enzymes are closely involved with eye diseases [23]. We have studied the expression of $17 \beta$-HSD and the effects of DEX in neural tissues of the rat eye.

\section{Materials and methods}

\subsection{Materials}

Sprague Dawley rats (SD rats) were purchased from the laboratory animal center of Jilin University (Changchun, China), Dexamethasone sodium phosphate $5 \mathrm{mg} / \mathrm{ml}$ (Zhuo Feng Pharmaceutical Factory of Zhengzhou, China), urethane (Heng Yuan biotech company of Shanghai, China) 15\%. Paraformaldehyde solution (Sen Bei Jia Pharmaceutical Factory of Nanjing, China) 4\%. Phosphate Buffer solution (PBS, $0.01 \mathrm{~mol} / \mathrm{L}$, HP 7.4), Tris-TBS concentration is $0.05 \mathrm{~mol} / \mathrm{L}$, Western Blot Buffer (Glycine $2.9 \mathrm{~g}$. Tris $5.8 \mathrm{~g}$, SDS $0.37 \mathrm{~g}$, Methanol, $200 \mathrm{ml}, \mathrm{H} 2 \mathrm{O}, 1000 \mathrm{ml})$, TBS Buffer (1 mol/L Tris·HCl (pH7.5) $10 \mathrm{ml}$. NaCl $8.8 \mathrm{~g}), 6 \mathrm{mg} / \mathrm{ml}$ BSA (blocking buffer). Rbbit anti-HSD17B1 (200 $\mu \mathrm{g} / \mathrm{ml}$, AVIVA Systems Biology, USA). Goat anti-rabbit IgG-HRP (1 mg/ml, ABCAM).

The rat holder, retort stand about 1 meter height, A pool, Y maze (the arms is $450 \mathrm{~mm}$ length, $145 \mathrm{~mm}$ breadth, $125 \mathrm{~mm}$ height), SYU Gel Imaging System (BIO-RAD,USA), FV1000 Laser Scanning Confocal Microscope (Olympus, Japan), CM 850 freezing microtome (Leica, Germany), OCT. Compound (Leica, Germany), UV spectrophotometer (Pu Yuan Metrologic Instruments of Shanghai, China) beaker, glass rod, test tube, graduated pipette, measuring cylinder, Constant temperature and humidity incubator, glass slide.

\subsection{Dexamethasone treatment assay}

The experimental animals were 6-8 weeks of age, 400-600 g weight, they are healthy, lively, and curious about everything. Rats fed for three days at the laboratory to adapt the animals to the environment. Then, DEX was intraperitoneally injected daily for 7 days. There were 5 groups ( 2 rats per group). The DEX was given at 5 different concentrations $(2 \mathrm{mg} / \mathrm{kg}, 1.5 \mathrm{mg} / \mathrm{kg}, 1 \mathrm{mg} / \mathrm{kg}, 0.5 \mathrm{mg} / \mathrm{kg}, 0.25 \mathrm{mg} / \mathrm{kg})$. 
After 7 days, the health status of the rats was observed. Y maze, tail suspension test and forced swimming among DEX and control groups were recorded.

\subsection{Extraction and measure of total protein}

Eyes from ethyl urethane anesthetized rats were obtained and the neural tissues were carefully dissected. Tissues were homogenized in $250 \mu \mathrm{l}$ cracking liquid (including PMSF) in an ice bath for $20 \mathrm{~min}$. and centrifuged at $4{ }^{\circ} \mathrm{C}(12000 \mathrm{rpm}$ for $5 \mathrm{~min})$. The supernatant was used for protein determination and ELISA.

The protein concentration of the samples was determined following the coomassie brilliant blue method in J. Steroid. Biochem. Mol. Biol [24], The OD is determined at 595 wavelength absorption values.

\subsection{Western Blot of $17 \beta-H S D 1$}

First the optic nerves just extracted from control rats, the retina detachment lysis buffer in homogenizer. centrifugation, collected supernatant liquor, supernatant was used for Western Blot. The sample protein concentration is $1.94 \mathrm{mg} / \mathrm{ml}$. The Western Blot was identified by the method of E. Maser in J. Steroid. Biochem. Mol. Biol [24]. Added rabbit anti-HSD17B1 (200 $\mu \mathrm{g} / \mathrm{ml}$, AVIVA Systems Biology, USA), dilution $1: 1000,25^{\circ} \mathrm{C}$, shake cultivation for $3 \mathrm{~h}$ and washed 3 times and added the second antibody goat anti-rabbit IgG-HRP $(1 \mathrm{mg} / \mathrm{ml}, \mathrm{ABCAM})$, dilution $1: 5000,25^{\circ} \mathrm{C}$, shake cultivation for $1 \mathrm{~h}$, washed 3 times. DAB and $\mathrm{H} 2 \mathrm{O} 2$ were mixed about $2 \mathrm{ml}$, and then put them into nitrocellulose filter, $5 \mathrm{~min}$ in the room temperature.

\subsection{Immunohistochemistry of $17 \beta-H S D 1$}

Retina tissues were got from DEX rats and controls. There are four samples from each group, right eye or left eye. The optic nerves put into the paraformaldehyde solution $30 \mathrm{~min}, 4^{\circ} \mathrm{C}$, then dip in $5 \%$, $15 \%, 35 \%$ sucrose solution dehydration 10 min one after another, OCT imbedding, sliced, washed, sealed. The sections were incubated with the first antibody, rabbit anti-HSD17B1 $(200 \mu \mathrm{g} / \mathrm{ml}$, AVIVA Systems Biology, USA), dilution $1: 100,4^{\circ} \mathrm{C}$, overnight and the second antibody donkey anti-rabbit IgGFITC $(2 \mathrm{mg} / \mathrm{ml}, \mathrm{ABCAM})$, dilution $1: 1000,25^{\circ} \mathrm{C}, 2 \mathrm{~h}$, then got the photo with laser scanning confocal microscope.

\subsection{Elisa of $17 \beta-H S D 1$ assay}

ELISA was used to measure the rat optic nerve of DEX-treated and control group. The control group was given sterile water, while the experiment group was given $17 \beta$-HSD1 protein to react with HSD17B1 antibody. Retina tissue lysis solution diluted 1:500 in PBS was put into the 96-well plate wells $\left(100 \mu \mathrm{L} /\right.$ plate) overnight at $4^{\circ} \mathrm{C}$ (the original concentration of protein is $1.94 \mathrm{mg} / \mathrm{ml}$ ), then washed three times for 2 min each time. After sealing with BSA $(100 \mu \mathrm{L} /$ plate, v $/ \mathrm{V}=5 \%)$ at $37^{\circ} \mathrm{C}$ for $1 \mathrm{~h}$, washed three times 2 min each time. $100 \mu \mathrm{L}$ of first Ab HSD17B1 antibody diluted 1:50, 1:100, 1:200, 1:400, 1:600, 1:800, 1:1000, 1:1200 (v/V) in PBS were added into each plate. After incubation for $2 \mathrm{~h}$, at $37^{\circ} \mathrm{C}$, washed three times for 2 min each time. Then, HRP Goat Anti-Rabbit Ig G diluted 1:6000 in PBS were added, and closed the lid at $37^{\circ} \mathrm{C}$ for $1 \mathrm{~h}$. Finally, washed three times for 2 min each time, then TMB substrates were added to stop the reaction. 
Table 1

The correct times rats found food in Y maze assay

\begin{tabular}{lcccccccccc}
\hline & A1 & A2 & A3 & A4 & A5 & C1 & C2 & C3 & C4 & C5 \\
\hline 1 day & 1 & 2 & 1 & 1 & 0 & 2 & 2 & 2 & 2 & 3 \\
2 day & 0 & 1 & 3 & 2 & 1 & 1 & 3 & 1 & 2 & 3 \\
3 day & 0 & 3 & 4 & 1 & 0 & 3 & 4 & 1 & 3 & 2 \\
4 day & 1 & 3 & 5 & 3 & 2 & 0 & 3 & 3 & 4 & 3 \\
5 day & 0 & 4 & 4 & 2 & 0 & 1 & 4 & 2 & 3 & 4 \\
6 day & 2 & 3 & 2 & 3 & 1 & 2 & 5 & 2 & 3 & 4 \\
7 day & 2 & 4 & 3 & 2 & 1 & 2 & 6 & 2 & 4 & 5 \\
Average & 0.86 & 2.57 & 2.85 & 2.0 & 0.71 & 1.57 & 3.86 & 1.86 & 3.0 & 3.38 \\
\hline
\end{tabular}

The table show correct times rats found food in Y maze assay. A1, A2, A3, A4, A5 group rats which treated with DEX, the C1, $\mathrm{C} 2, \mathrm{C} 3, \mathrm{C} 4, \mathrm{C} 5$ was the control groups. It is obviously in 7 days training healthy rats give more times in founding food average 2.8 , but the experimental group just 2 in one minute.

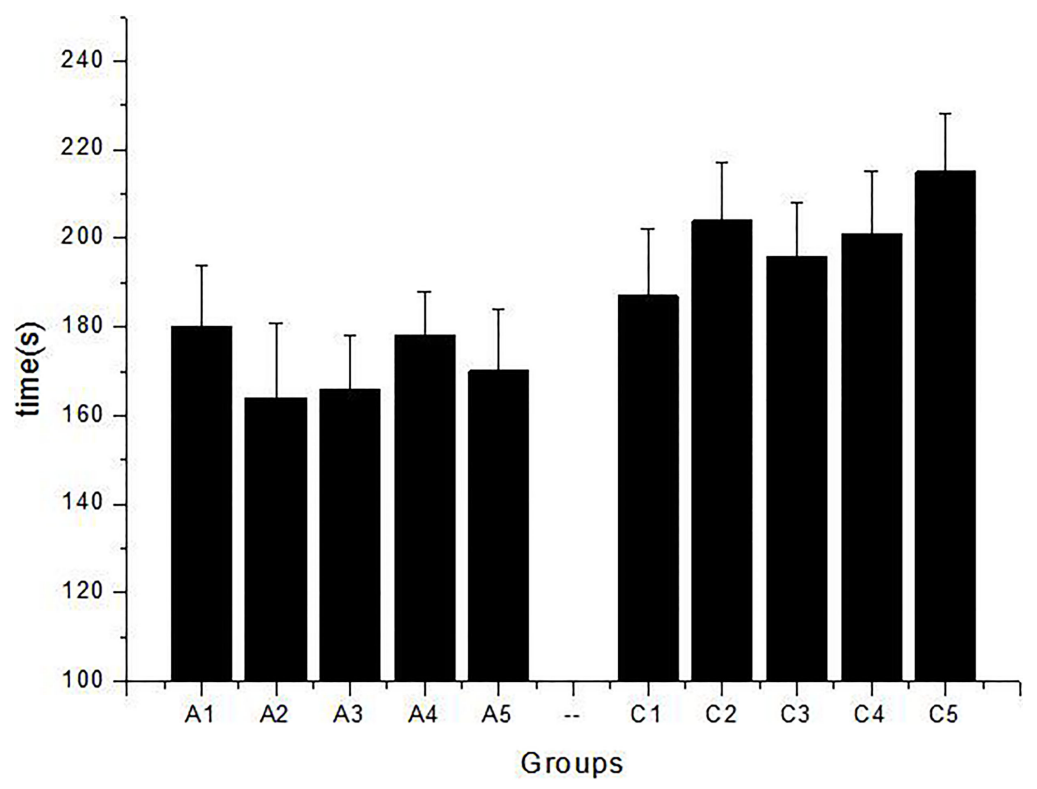

Fig. 1. The picture was drawn by the average data in 7 days, each data measured 3 times, A1, A2, A3, A4, A5 group rats which treated with DEX, the C1, C2, C3, C4, C5 was the control groups. Mean is $171.6 \pm 13.4 \mathrm{~s}$ and $200.6 \pm 14 \mathrm{~s}$. Tail suspension test shows experimental group got depression more easily than control.

\section{Results}

\subsection{Dexamethasone treatment results}

The SD rats injected intraperioneally with EDX in $2 \mathrm{mg} / \mathrm{kg}, 1.5 \mathrm{mg} / \mathrm{kg}, 1 \mathrm{mg} / \mathrm{kg}$ are death, $0.5 \mathrm{mg} / \mathrm{kg}$ and $0.25 \mathrm{mg} / \mathrm{kg}$ groups are alive so the limiting concentration chose $0.75 \mathrm{mg} / \mathrm{kg}$ for the experimental group. Control group was also measured by giving the same amount of physiological saline.

Seven day's data were taken, the average value were calculated and given in Table 1, A1, A2, A3, A4, A5 are the rats injected with DEX, indicating the food average is $2 \mathrm{~s} / \mathrm{min}$, but $\mathrm{C} 1, \mathrm{C} 2, \mathrm{C} 3, \mathrm{C} 4, \mathrm{C} 5$ of the control group indicate the food average is $2.8 \mathrm{~s} / \mathrm{min}$ in $\mathrm{Y}$ maze. Tail suspension test shows the average time to give up struggling is $172 \mathrm{~s}$ in, but the blank is $200.6 \mathrm{~s}$ in average, which is decreased by $14.3 \%$. So, the DEX has negative influence for rats in emotion or exercise capacity (Fig. 1). Forced swimming 


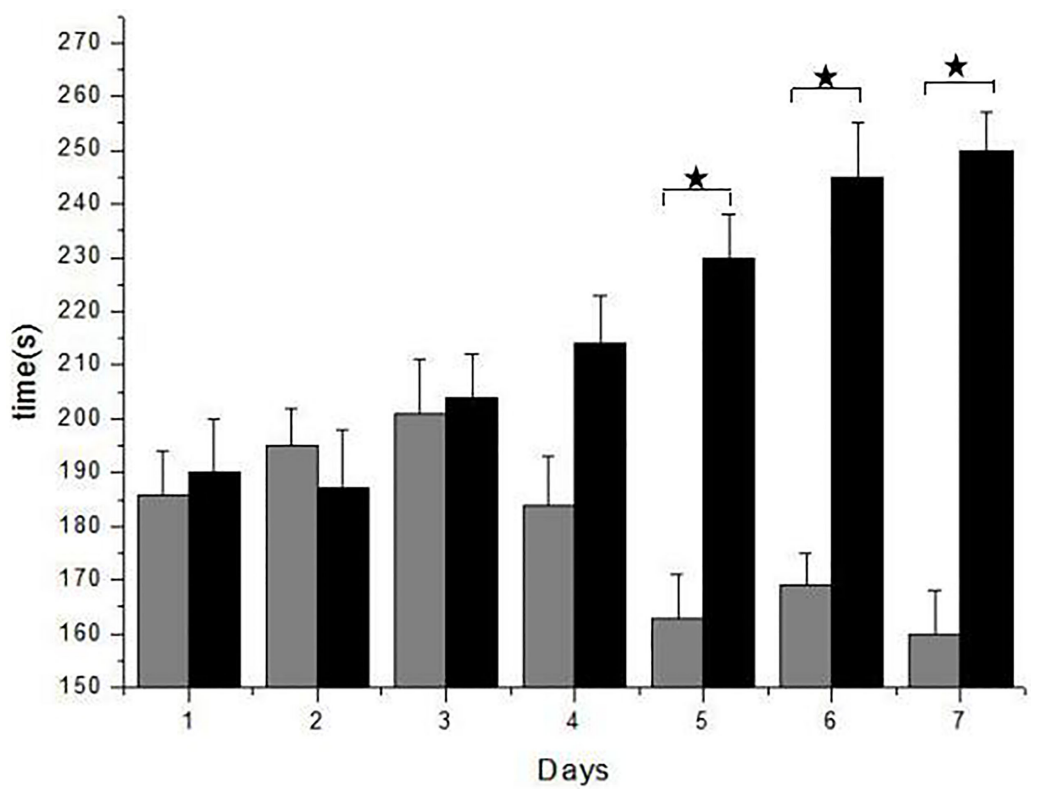

Fig. 2. Forced Swimming Test (FST) shows rats with the DEX exercise capacity and the faculty of memory. It is obvious the test results are similar in 3 days, but after the fourth day, the score improved. In the control group rats adapting the swimming, the physical strength and memory became much worse than control rats. Especially the fifth, sixth, seventh day, experimental group took more time, it is $67 \pm 2 \mathrm{~s}, 76 \pm 4 \mathrm{~s}, 90 \pm 1 \mathrm{~s}$. DEX group are in gray. The control group are in black. Data are shown as the means \pm standard error of the means, ${ }^{*} p<0.05$.

test observation records the time of rats got in desperate state in the water. Struggling time reduces to $19.25 \%$ for DEX group, but it is increased to $33.68 \%$ for control group (Fig. 2).

\subsection{Extract and measure total protein}

Standard curve of protein was drawn by coomassie brilliant blue method, based on the gradient dilution technique of BSA solution. The linear regression equation was $y=0.0055 * x-0.0053, R^{2}=$ 0.9987 .

The sample was measured by three times, the absorption values were got at a wavelength of $595 \mathrm{~nm}$, and then calculated according to the standard curve. The average concentration of total protein was $1.94 \mathrm{mg} / \mathrm{ml}$.

\subsection{Western Blot of $17 \beta$-HSDI}

To explore the $17 \beta$-HSD1 protein exists in the retina of normal rat. The total protein was got from retina and analyzed by Western Blot. The PVDF filter shows the gray's mark of $17 \beta$-HSD1 (Fig. 3). It is about $44 \mathrm{KD}$.

\subsection{Immunohistochemistry of $17 \beta-H S D 1$}

The result of Immunohistochemistry (IHC) test 17 $\beta$-HSD1 on rat optic nerve was shown in the Fig. 4. In the picture it is clear shown about layers of retina, inner limiting membrane, nerve fiber layer, ganglion cell layer, inner plexiform layer, inner nuclear layer, outer plexiform layer and outer nuclear layer 
Table 2

Elisa assay OD595 of $17 \beta$-HSD1

\begin{tabular}{lcccccccccc}
\hline Sample & $17 \beta$-HSD1 & $1: 50$ & $1: 100$ & $1: 200$ & $1: 400$ & $1: 600$ & $1: 800$ & $1: 1000$ & $1: 1200$ & Control \\
\hline DEX & $1.74 \pm$ & $1.51 \pm$ & $1.37 \pm$ & $1.11 \pm$ & $0.51 \pm$ & $0.2 \pm$ & $0.12 \pm$ & $0.09 \pm$ & $0.08 \pm$ & $0.18 \pm$ \\
& 0.07 & 0.08 & 0.09 & 0.07 & 0.12 & 0.08 & 0.05 & 0.02 & 0.03 & 0.03 \\
Control & $0.73 \pm$ & $0.57 \pm$ & $0.44 \pm$ & $0.31 \pm$ & $0.23 \pm$ & $0.17 \pm$ & $0.12 \pm$ & $0.1 \pm$ & $0.09 \pm$ & $0.02 \pm$ \\
& 0.08 & 0.07 & 0.1 & 0.06 & 0.07 & 0.04 & 0.05 & 0.03 & 0.04 & 0.02 \\
\hline
\end{tabular}

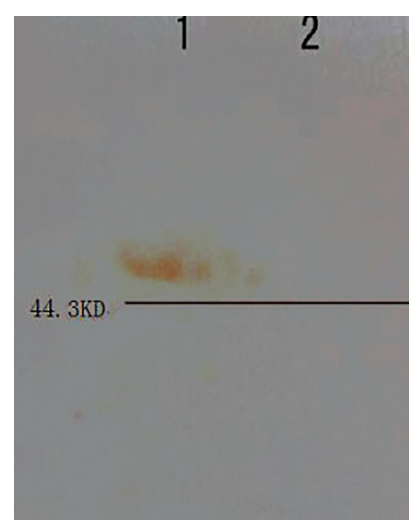

Fig. 3. Western Blot of $17 \beta$-HSD1 enzyme on rat optic nerve, on the picture lane 1 track is the rat optic nerve sample and lane 2 track is the blank with no sample.

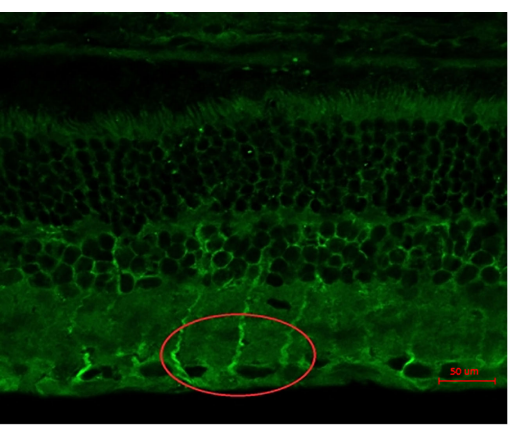

a

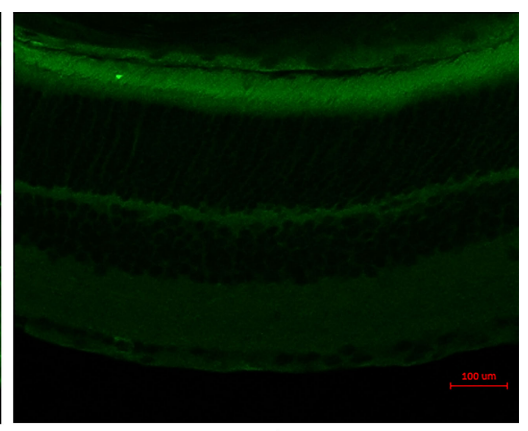

b

Fig. 4. IHC shows $17 \beta$-HSD1 enzyme on rat optic nerve. The left shows green signal on layers of retina, inner limiting membrane, nerve fiber layer, ganglion cell layer, inner plexiform layer, inner nuclear layer, outer plexiform layer and outer nuclear layer with red circle in experimental group, the right shows control rats have no signals in retina.

(Fig. 4a), but there is no signal in control groups (Fig. 4b). This experiment shows $17 \beta$-HSD1 enzyme is in the rat retina. IHC shows the green signal on retina ganglion cell layer about Muller cells with red circle, which is consistent with the previous reported that hormone enzyme may expressed in glial cells [25].

\subsection{Elisa of $17 \beta-H S D 1$}

The results show the $17 \beta$-HSD1 content of DEX group is 2.4 times higher than control group (Table 2, Fig. 5), indicating that $17 \beta$-HSD1 takes part in DEX metabolism on rat optic nerve, it plays an important role in local regulation of hormone level. 


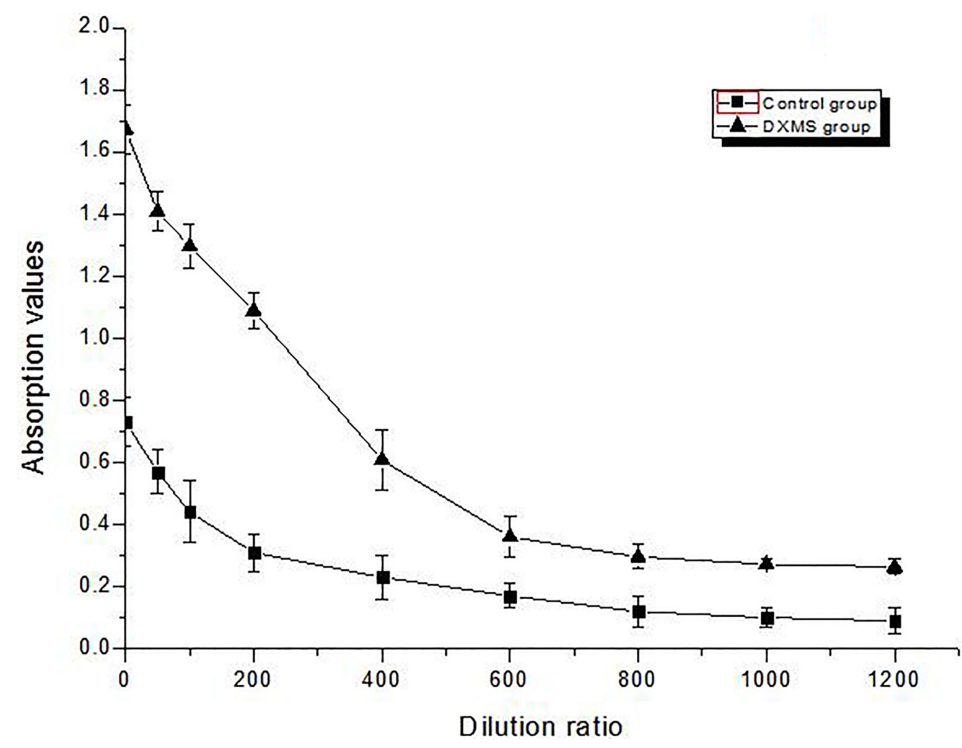

Fig. 5. Elisa assays the content of $17 \beta$-HSD1 in DEX groups and control groups. In the picture the abscissa is $17 \beta$-HSD1 antibody with PBS dilute in 1:50, 1:100, 1:200, 1:400, 1:600, 1:800, 1:1000, 1:1200 (v/V), the ordinate is absorption values in $595 \mathrm{~nm}$. the square means DEX group and triangle is control.

\section{Discussion}

Bisphenol A, pesticide and DEX are synthetic estrogen; they can combine with hormone receptor or mimic hormones signaling pathways. They act like endogenous estrogen, because their structure are highly similar to endogenous hormones [26], leading to excessive accumulation of endogenous hormone, and making the body endocrine disorder, may even suffer from some diseases [27]. The endogenous hormone also plays an important role in our eyes, and involve in many biochemical reactions, so the abnormal level of hormone often causes eye diseases [28]. DEX is belong to steroid hormone and widely used in our life such as anti-inflammatory drugs, rheumatic drugs, allergies drugs, asthma drugs, chronic obstructive pulmonary drugs. So it has important significance to study the effects of excess DEX on our retina.

This paper has studied about the relationship between DEX and retina. DEX has negative effect on exercise, metabolism, memory of rat (Table 1, Figs 1 and 2), and this damage could not recover. Western Blot results show that $17 \beta$-HSD1 express in optic nerve (Fig. 3). IHC experiments marked $17 \beta$-HSD1 in inner nuclear layer, inner plexiform layer, and ganglion cell layer on the rat retina (Fig. 4). ELISA experiment results show that $17 \beta$-HSD1 content in DEX group is 2.4 times higher than the control group (Fig. 5). This is interesting, as we known DEX is suppress growth hormone (GH), luteinizing Hormone (LH), follicle-stimulating hormone (FSH), estradiol (E2) and progesterone (P). 17 $\beta$-HSD is a group of alcohol oxidoreductases which catalyze the reduction of 17-ketosteroids and dehydrogenation of $17 \beta$-hydroxysteroids in steroidogenesis and steroid metabolism [30]. This includes interconversion of DHEA, testosterone, estrone and estradiol [31]. Because a large amount of DEX was used in rats during the experiment process, it needed a short time to complete the metabolism of these cortisone hormones. It is bound to cause high expression of HSD family enzymes. We also know that $11 \mathrm{hsd}$ is a key enzyme for the metabolism of cortisone. It is speculated that $17 \mathrm{hsd}$ will be involved in the DEX degradation of many downstream metabolites, but it still lacks direct evidence. 
In short, we have studied the effects of hormone on optic nerve, the regulation relationship of enzymes involved in hormone, enzyme activity and optic nerve physiology, which is worth exploring.

\section{Acknowledgments}

This scientific research project was supported by the Education Development Plan of Jilin Province of the People's Republic of China (JJKH20190603KJ).

\section{Conflict of interest}

None to report.

\section{References}

[1] Provan D, Stasi R, Newland AC, Blanchette VS, Bolton-Maggs P. International consensus report on the investigation and management of primary immune thrombocytopenia. Blood. 2010; 115: 168-186. DOI: 10.1182/blood-2009-06-225565.

[2] Mohan K, Kecova H, Hernandez-Merino E, Kardon RH, Harper MM. Retinal ganglion cell damage in an experimental rodent model of blast-mediated traumatic brain injury. Investigative Opthalmology \& Visual Science. 2013; 54(5): 34403450. DOI: $10.1167 /$ iovs.12-11522.

[3] Gracitelli CP, Duque-Chica GL, Moura AL, Nagy BV, Paranhos A Jr, et al. A positive association between intrinsically photosensitive retinal ganglion cells and retinal nerve fiber layer thinning in glaucoma. Investigative Ophthalmology \& Visual Science. 2014; 55(12): 7997-8005. DOI: 10.1167/iovs.14-15146.

[4] Cascio C, Deidda I, Russo D, Guarneri P. The estrogenic retina: The potential contribution to healthy aging and agerelated neurodegenerative diseases of the retina. Steroids. 2015; 103: 31-41. DOI: 10.1016/j.steroids.2015.08.002.

[5] Prokai-Tatrai K, et al. $17 \beta$-estradiol eye drops protect the retinal ganglion cell layer and preserve visual function in an in vivo model of glaucoma. Molecular Pharmaceutics. 2013; 10(8): 3253-3261. DOI: 10.1021/mp400313u.

[6] Kador KE, Montero RB, Venugopalan P, Hertz J, Zindell AN, Valenzuela DA, Uddin MS, Lavik EB, et al. Tissue engineering the retinal ganglion cell nerve fiber layer. Biomaterials. 2013; 17: 4242-4250. DOI: 10.1016/j.biomaterials. 2013.02.027.

[7] Cassetta A, Krastanova I, Kristan K, et al. Insights into subtle conformational differences in the substrate-binding loop of fungal $17 \beta$-hydroxysteroid dehydrogenase: a combined structural and kinetic approach. Biochemical Journal. 2012; 441(1): 151-160. DOI: 10.1042/BJ20110567.

[8] Marchais-Oberwinkler S, Henn C, Möller G, Klein T, Negri M, Oster A, Spadaro A, Werth R, et al. 17 $\beta$-hydroxysteroid dehydrogenases (17 $\beta$-HSDs) as therapeutic targets: protein structures, functions, and recent progress in inhibitor development. Steroid. Biochem. Mol. Biol. 2011; 125: 66-82. DOI: 10.1016/j.jsbmb.2010.12.013.

[9] Svegelj MB, Stojan J, Rizner TL. The role of Ala231 and Trp227 in the substrate specificities of fungal $17 \beta$ hydroxysteroid dehydrogenase and trihydroxynaphthalene reductase: steroids versus smaller substrates. Journal of Steroid Biochemistry \& Molecular Biology. 2012; 129(1-2): 92-98. DOI: 10.1016/j.jsbmb.2011.03.019.

[10] Lajic S, Nordenström A, Hirvikoski T. Long-term outcome of prenatal dexamethasone treatment of 21-hydroxylase deficiency. Endocrine Development. 2011; 20: 96-105. DOI: 10.1159/000321228.

[11] Kawa L, Barde S, Arborelius UP, Theodorsson E, Agoston D, Risling M, Hökfelt T. Expression of galanin and its receptors are perturbed in a rodent model of mild, blast-induced traumatic brain injury. Experimental Neurology. 2016; 279: 159-167. DOI: 10.1016/j.expneurol.2016.02.019.

[12] Adamski J, Jakob FJ. A guide to $17 \beta$-hydroxysteroid dehydrogenases. Mol. Cell. Endocrinol. 2001; 171(1-2): 1-4. DOI: 10.1016/S0303-7207(00)00383-X.

[13] Li M, Xiong G, Maser E. A novel transcriptional repressor PhaR for the steroid-inducible expression of the 3,17 $\beta$ hydroxysteroid dehydrogenase gene in Comamonas testosteroni ATCC11996. Chem-biol. Interact. 2013; 202(1-3): 116125. DOI: $10.1016 /$ j.cbi.2012.12.014.

[14] Morrison JC, Moore CG, Deppmeier LMH, et al. A rat model of chronic pressure-induced optic nerve damage. Experimental Eye Research. 1997; 64(1): 85-96. DOI: 10.1006/exer.1996.0184.

[15] Ma W, Cojocaru R, Gotoh N, et al. Gene expression changes in aging retinal microglia: relationship to microglial support functions and regulation of activation. Neurobiology of Aging. 2013; 34(10): 2310-2321. DOI: 10.1016/j.neurobiolag ing.2013.03.022. 
[16] Ma W, Wong WT. Aging changes in retinal microglia and their relevance to age-related retinal disease. Advances in Experimental Medicine and Biology. 2016; 854: 73-78. DOI: 10.1007/978-3-319-17121-0_11.

[17] Xiong G, Maser E. Regulation of the steroid-inducible $3 \alpha$-hydroxysteroid dehydrogenase/carbonyl reductase gene in comamonas testosteroni. J. Biol. Chem. 2001; 276(13): 9961-9970. DOI: 10.1074/jbc.M010962200.

[18] Meier M, Möller G, Adamski J. Perspectives in understanding the role of human 17 $\beta$-hydroxysteroid dehydrogenases in health and disease. Annals of the New York Academy of Sciences. 2009; 1155(1): 15-24. DOI: 10.1111/j.17496632.2009.03702.x.

[19] Jaliffa CO, Howard S, Hoijman E, et al. Effect of neurosteroids on the retinal gabaergic system and electroretinographic activity in the golden hamster. Journal of Neurochemistry. 2005; 94(6): 1666-1675. DOI: 10.1111/j.14714159.2005.03321.x.

[20] Kumar DM, Simpkins JW, Agarwal N. Estrogens and neuroprotection in retinal diseases. Molecular Vision. 2008; 14(14): 1480-1486

[21] Dhindsa S, Furlanetto R, Vora M, et al. Low estradiol concentrations in men with subnormal testosterone concentrations and type 2 diabetes. Diabetes Care. 2011; 34(8): 1854-1859. DOI: 10.2337/dc11-0208.

[22] Jiang M, Luo X, Shen Y, et al. Neuroprotection of estrogen receptor GPR30 in retinal ganglion cell. Medical Journal of Wuhan University. 2016; 37(2): 195-199. DOI: 10.14188/j.1671-8852.2016.02.006.

[23] Sposato V, Parisi V, Manni L, et al. Glaucoma alters the expression of NGF and NGF receptors in visual cortex and geniculate nucleus of rats: Effect of eye NGF application. Vision Research. 2009; 49(1): 54-63. DOI: 10.1016/j.visres. 2008.09.024.

[24] Gong W, Xiong G, Maser E. Cloning, expression and characterization of a novel short-chain dehydrogenase/reductase (SDRx) in Comamonas testosteroni. Journal of Steroid Biochemistry and Molecular Biology. 2012; 129(1-2): 15-21. DOI: $10.1016 / j . j s b m b .2010 .11 .008$.

[25] Saiegh L, Keren D, Rainis T, Sheikh-Ahmad M, et al. Dexamethasone suppressed corticotropin-releasing hormone stimulation test in morbid obese adults. Obesity Research \& Clinical Practice. 2016; 10(3): 275-282. DOI: 10.1016/j.orcp.2015.07.004.

[26] Fudvoye J, Bourguignon JP, Parent AS. Chapter one-endocrine-disrupting chemicals and human growth and maturation: a focus on early critical windows of exposure. Vitamins \& Hormones-advances in Research \& Applications. 2014; 94(1): 1-25. DOI: 10.1016/B978-0-12-800095-3.00001-8.

[27] Warris LT, van den Akker ELT, Aarsen FK, et al. Predicting the neurobehavioral side effects of dexamethasone in pediatric acute lymphoblastic leukemia. Psychoneuroendocrinology. 2016; 72: 190-195. DOI: 10.1016/j.psyneuen. 2016.07.006.

[28] Cacciaglia R, Nees F, Grimm O, et al. Trauma exposure relates to heightened stress, altered amygdala morphology and deficient extinction learning: Implications for psychopathology. Psychoneuroendocrinology. 2017; 76: 19-28. DOI: 10.1016/j.psyneuen.2016.11.012.

[29] Opere CA, Heruye S, Njiembye YF, et al. Regulation of excitatory amino acid transmission in the retina: Studies on neuroprotection. J Ocul Pharmacol Ther. 2018; 34(1-2): 245-256. DOI: 10.1093/ijnp/pyx096.

[30] Talalay P, Dobson MM. Purification and properties of a beta-hydroxysteroid dehydrogenase. Biological Chemistry. 1953; 205(2): 823-837. DOI: 10.1016/S0074-7696(08)61042-6.

[31] Labrie F, Luu-The V, Lin SX, Labrie C, Simard J, Breton R, Bélanger A. The key role of 17 beta-hydroxysteroid dehydrogenases in sex steroid biology. Steroids. 1997; 62(1): 148-158. 